\title{
Modelization and Simulation of an Electric and Fuel Cell Hybrid Vehicle under Real Conditions
}

\author{
By Alfonsin ${ }^{1}$, R. Maceiras ${ }^{1}$, A. Cancela ${ }^{2}$, A. Sanchez ${ }^{2}$
}

\begin{abstract}
This paper presents a toolbox for the simulation of a zero emission urban hybrid bus, which combines batteries and fuel cells. This type of vehicle performs predefined routes with a certain frequency, then they are an ideal option to the replacement of combustion engines with renewable energy systems. The simulation of these vehicles can be made for different standard driving cycles (ECE-15, EUDC, NEDC, SFUDS) or for real routes from GPS device data. This will allow to consider the orography of the route, considering the slope that overcomes the vehicle at each time, generally this parameter is not included in other models, and it could become a determining factor for the applicability of these vehicles on certain specified routes. Moreover, this tool lets to study and to analyse other not easily quantifiable factors, such as the weather or peak-hour traffic. Finally, the performance of an urban hybrid bus was investigated to assess its theoretical range and the technical feasibility of zero-emission vehicles.
\end{abstract}

Keywords: Electric vehicle; Battery; Fuel cell; Hydrogen; Simulation

\section{Introduction}

The increase of energetic environmental problems and the constant increase in oil prices have favoured the development of alternative energy systems (Sorrentino, Pianese, \& Maiorino, 2013). For this reason in the last years, automotive industry has introduced more efficient fuels vehicles that reduce gas emissions (Hannan, Azidin, \& Mohamed, 2014) and minimize the use of combustion engines replacing them by electric systems or hybrid systems with several kind of power sources (Li, Chen, Li, Liu, \& Huang, 2012). One potential technologies to receive attention is the hybrid electric vehicle, which consists of two or more energy sources that supply energy to electric traction motors that in turn drive the wheels (Achour, Carton, \& Olabi, 2011; Kuramochi, Ramírez, Turkenburg, \& Faaij, 2013; Pollet, Staffell, \& Shang, 2012).

Fuel cell vehicle appears as a serious candidate for the substitution of gasoline cars as it was in the past (Wang, Zhou, Hong, Qiu, \& Wang, 2005). They could solve environmental problems, contribute the accomplishment of Kyoto Protocol, and besides they can help to solve the oil dependence (Anandarajah, McDowall, \& Ekins, 2013; Chen, 2012). Nevertheless, this technology is only suitable for consumers whose trips are mostly made within small distances. And hydrogen storage and distribution complexities are other drawbacks of the electric car battery. Then, the plug-in hybrid vehicle equipped with a small combustion engine for large trips would probably facilitate the introduction of this technology (Bento, 2010), resulting in an alternative to the hydrogen fuel cell vehicle.

The purpose of this paper is to present a simulation tool for actual hybrid vehicles routes, mainly buses, and freely distributed as a Matlab/Octave toolbox, called SimuBus, which has been gifted in with a graphical interface that simplifies the use and results interpretation (Matlab version only). This toolbox allows a first assessment of the applicability of both electric buses, as fuel cell

${ }^{2}$ Chemical Engineering Department, EEI, University of Vigo, 36310 Vigo, Spain. 
or hybrid (fuel cell-battery) in different scenarios, including the possibility to analyze various traffic conditions for the same journey. Importing data via GPS or digital maps strengthens the predictability of car range in different places without the need of "in situ" testing.

\section{Toolbox Structure}

This simulation toolbox is performed using several configuration screens: the mechanical vehicle setup, the energy supply systems (battery and fuel cell), electric motor configuration and the route characterization. Fig. 1 shows the graphical user interface developed under Matlab® environment.

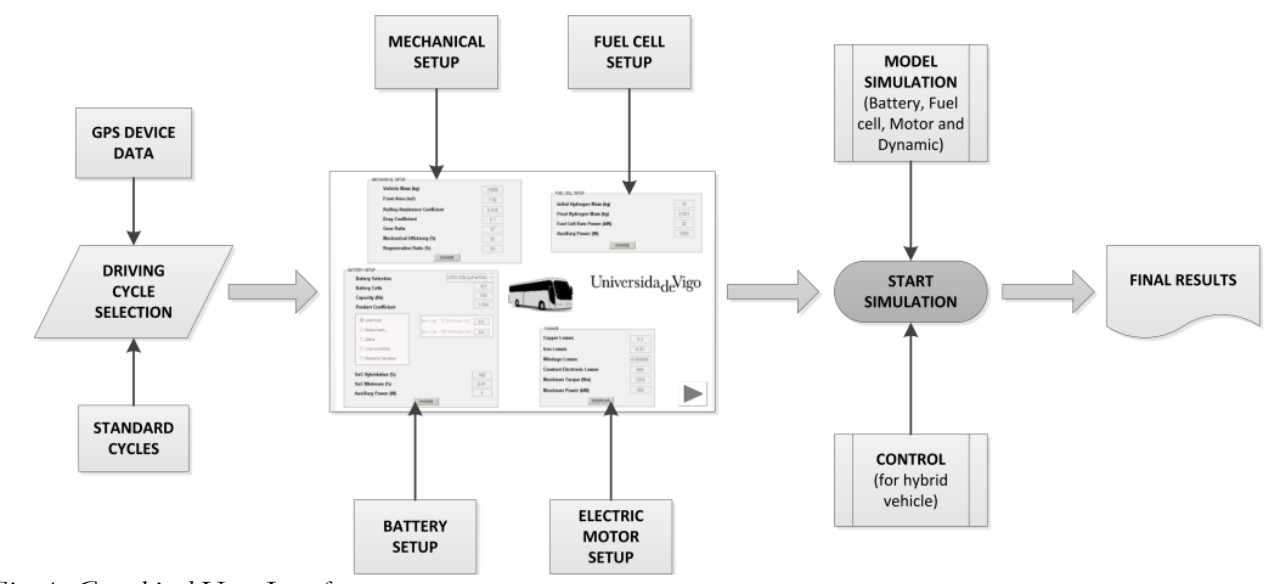

Fig. 1: Graphical User Interface

In this interface, the first step will be to choose one route. And for this task, SimuBus allows the selection of standard driving cycles (ECE-15, SFUDS, EUDC and NEUDC) or load data from a GPS device for real routes. Next step, it will be the setup of all bus elements, a panel with the mechanical setup lets to change several parameters as the rolling resistance, drag coefficient, frontal area, gear ratio and mechanical transmission efficiency. In other panel, electric motor and controller can also be set. And finally, battery and fuel cell can be configured. In the case of battery, the battery technology can be chosen among the most commons.

\section{Vehicle Dynamic Model}

The main objective of this dynamical model is to obtain the necessary mechanical power for the vehicle movement that should be provided by the electric motor. For the purpose of estimating this value, the sum of all movement forces is used. Solving this equation for each of the different forces and multiplying with speed $(v)$ and the gear transmission $\left(\eta_{g}\right)$, the mechanical power for the vehicle movement is obtained. The obtained equation is the following (Larminie \& Lowry, 2003):

$P_{\text {mec } h}=\left(\mu_{r r} m g+\frac{1}{2} \rho A C_{d} v^{2}+m g \sin \theta+m a+I \frac{G^{2}}{\eta_{g} r^{2}} a\right) \cdot v \cdot \eta_{g}$

where $\mu_{r r}$ is the resistance rolling coefficient, $m$ the buss mass, $g$ is the gravity constant, $\rho$ is the air density, $A$ is the frontal area, $C_{d}$ is the drag coefficient, $\theta$ is the angle of climb, $I$ is the moment of inertia, $G$ is the gear ratio, $r$ is the radius of tire and $\eta_{g}$ is the gear system efficiency. 


\section{Battery Model}

This model predicts the dynamic behaviour of the battery, as much in the charge as in the discharge process. The battery dynamic behaviour is modelled through a simple battery equivalent circuit as a voltage source in series with a resistance. The open circuit voltage is implemented as Matlab ${ }^{\circledR}$ Function which depends of battery state of charge (SoC). The battery capacity is influenced by intensity magnitude during the charge and discharge. The grade of this effect depends on battery technology used. To correct this, battery model includes next Peukert's equation with the purpose of estimating the available capacity (Peukert, 1897).

\section{Fuel cell consumption model}

The used model in this toolbox has been a hydrogen consumption model instead of a fuel cell model. An equation to model the hydrogen intake as a function of power demanded by the fuel cell (by the motor and the auxiliary systems) can be used. Thus, based on the simple reaction stoichiometry (Larminie \& Dicks, 2003) which depends of power demanded by the fuel cell $\left(P_{\text {electric }}\right)$, the Faraday's Constant $(F)$ and the stack potential $\left(V_{c}\right)$, the following equation is obtained. It yields the hydrogen mass flux $\left(H_{2}\right.$ usage $)$, in moles per second, which makes possible to know the hydrogen consumption at each moment.

$H_{2 \text { usage }}=\frac{P_{\text {electric }}}{2 V_{c} F}$

\section{Electric Motor Model}

Once the output mechanical power of the electric motor is estimated, the electrical power demand can be calculated, too. To do this, the motor efficiency, or if that is not possible, the motor losses (copper conductor, iron losses, friction and windage losses, constant losses) must be known. By calculating the efficiency and using the angular speed and motor torque, the input electric power can be determined. Adding the auxiliary element power demand, the total electric power demand that the batteries and/or the fuel cell must supply can be obtained (Auinger, 1999; Larminie \& Lowry, 2003).

\section{Power Management}

A logic control model for vehicle energy management was developed and implemented on this toolbox (Fig. 2). The management depends on several parameters, the main are: total electric power demanded (Pelect), fuel cell stack power (Pfc), battery power (Pbat), battery and hydrogen state of charge (SoC). Moreover, the control includes an important configurable parameter called $S_{0} C_{-} H Y B$, which is used to change the energy management mode. SoC_HYB indicates when battery and fuel cell hybrid system begins to run in hybrid parallel mode. 


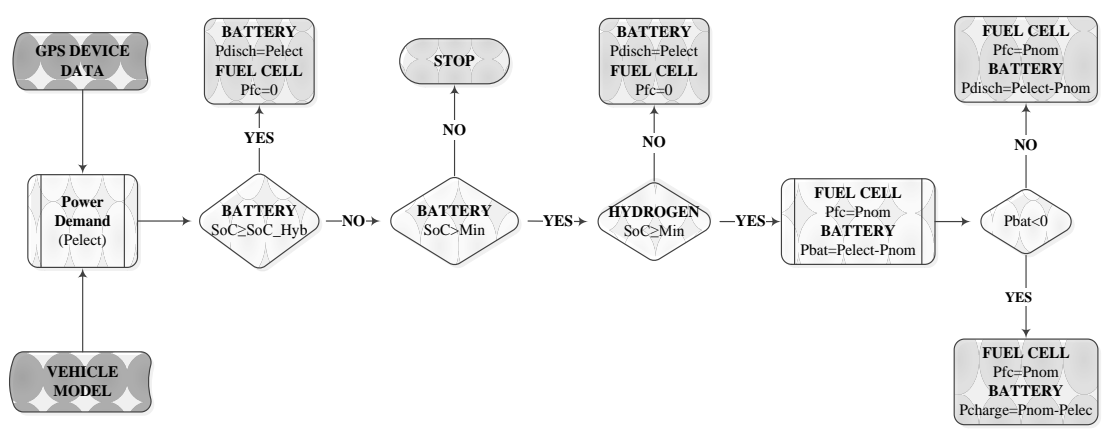

Fig. 2: Controller's Algorithm

If battery $S O C$ is below $S_{0} C_{-} H Y B$, the energy management changes from the battery mode to the parallel one. The main advantage of this parameter is to the possibility of choosing the preference of spending the hydrogen energy of the battery energy.

\section{Simulation}

Once this toolbox design is performed, a real route with a zero emission bus has been simulated. Fig. 3 shows the cycle realised with an urban bus, vehicle speed and altitude are represented in this graph.

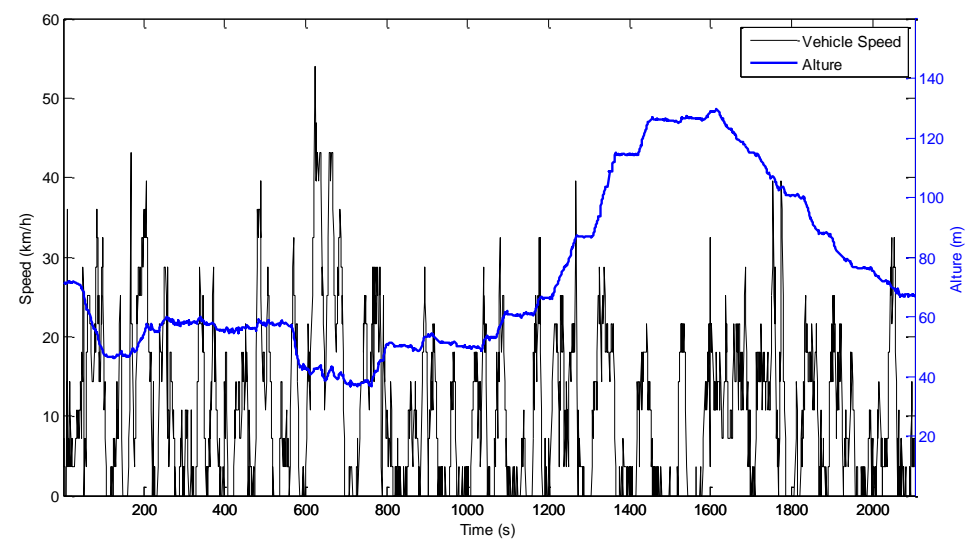

Fig. 3: Real bus route

Firstly, a commercial pure electric bus simulation was launched, and then it was compared with a hybrid system with a fuel cell. The selected electric commercial bus was from Winston manufacturer (EV-2012). The battery system technology used in this vehicle is a $\mathrm{LiFePO}_{4}$ (WBLYP700AHA). And for hybrid mode, the selected fuel cell was a $20 \mathrm{~kW}$ PEMFC of Hydrogenics (HyPM). The hydrogen mass available was $10 \mathrm{~kg}$ of $\mathrm{H}_{2}$. This fuel cell and hydrogen mass are easily implemented in this bus, due to its small size. In this case SoC_hyb was set with a value of 1 , thus hybrid bus simulation would start in parallel mode. It was considered that the hydrogen source is from renewable nature in an energy station, and the cost is zero. The final results of these simulations are collected in Table 1. 
Table 1: Electric Bus Simulated

\begin{tabular}{lcccc}
\hline Real Driving Cycle & \multicolumn{2}{c}{ Pure Electric } & \multicolumn{2}{c}{ Hybrid } \\
\hline & W/O Slope & W Slope & W/O Slope & W Slope \\
Cycles & 12 & 7.5 & 16.3 & 9.7 \\
Range $(\mathrm{km})$ & 71.77 & 45.37 & 98.23 & 58.07 \\
Simulation Time FCV/BEV (hour) & 6.87 & 4.33 & $6.62 / 2.78$ & $5.46 / 0.05$ \\
Maximum Torque (N.m) & 660.58 & 1370.00 & 660.58 & 1370.00 \\
Maximum Motor Power (kW) & 300.00 & 300.00 & 300.00 & 300 \\
Maximum Battery Power (kW) & 425.25 & 848.50 & 425.25 & 825.50 \\
\hline
\end{tabular}

In order to check the correct sizing of all elements, Fig. 4 shows as the power required is supplied in each instant of time. The real cycle was correctly simulated, thus the power system sizing is correct.
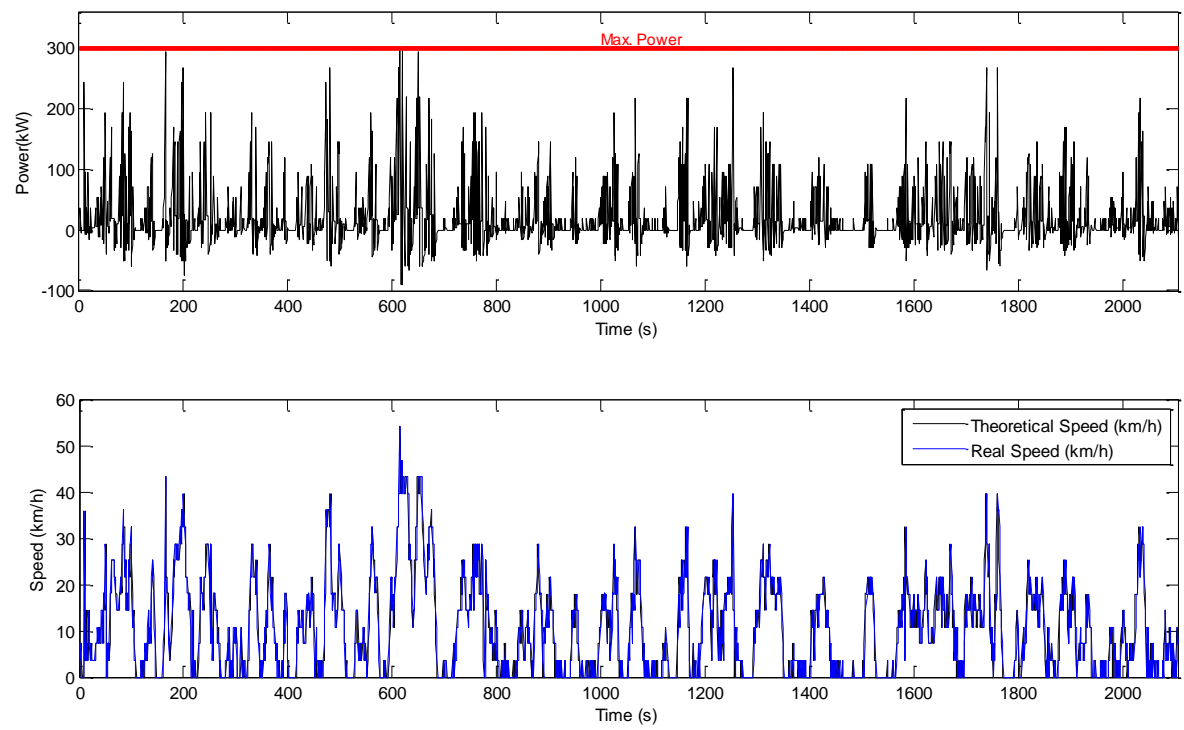

Fig.4: One cycle power demand (up) and influence of the energy sizing in the real cycle (down)

\section{Conclusions}

A toolbox for the simulation of electric-only or hybrid electric hydrogen vehicles is presented. This toolbox facilitates the evaluation of vehicle range (autonomy) for real travel, taking into account physical variables that are not taken into account in tools based on standard cycles. The principal advantage of this toolbox is that it can be used in the vehicle design stage because all components are parameterizable. Moreover, GPS data simulation makes possible to obtain a more precise range value. This value can be obtained by means of standard drive cycles because real data can be affected by parameters such as traffic density and weather. The influence of these parameters on the vehicle speed is considered. 


\section{References}

Achour, H., Carton, J. G., \& Olabi, A. G. (2011). Estimating vehicle emissions from road transport, case study: Dublin city. Applied Energy, 88(5), 1957-1964.

Anandarajah, G., McDowall, W., \& Ekins, P. (2013). Decarbonising road transport with hydrogen and electricity: Long term global technology learning scenarios. International Journal of Hydrogen Energy, 38(8), 3419-3432. doi:10.1016/j.ijhydene.2012.12.110

Auinger, H. (1999). Determination and designation of the efficiency of electrical machines. Power Engineering Journal, 13(1), 15-23.

Bento, N. (2010). Dynamic competition between plug-in hybrid and hydrogen fuel cell vehicles for personal transportation. International Journal of Hydrogen Energy, 35(20), 11271-11283. doi:http://dx.doi.org/10.1016/j.ijhydene.2010.07.103

Chen, P. (2012). Configuration of solar-hydrogen mild hybrid fuel cell power systems for electric vehicles. Journal of Power Sources, 201(0), 243-252. doi:10.1016/j.jpowsour.2011.10.126

Hannan, M. A., Azidin, F. A., \& Mohamed, A. (2014). Hybrid electric vehicles and their challenges: A review. Renewable and Sustainable Energy Reviews, 29(0), 135-150. doi:http://dx.doi.org/10.1016/j.rser.2013.08.097

Kuramochi, T., Ramírez, A., Turkenburg, W., \& Faaij, A. (2013). Techno-economic prospects for CO2 capture from distributed energy systems. Renewable and Sustainable Energy Reviews, 19(0), 328-347. doi:http://dx.doi.org/10.1016/j.rser.2012.10.051

Larminie, J., \& Lowry, J. (2003). Electric vehicle technology explained. Oxford: John Wiley \& Sons.

Larminie, J., \& Dicks, A. (2003). Fuel cell systems explained. Oxford: John Wiley \& Sons Ltd.

Li, Q., Chen, W., Li, Y., Liu, S., \& Huang, J. (2012). Energy management strategy for fuel cell/battery/ultracapacitor hybrid vehicle based on fuzzy logic. International Journal of Electrical Power \& Energy Systems, 43(1), 514-525. doi:10.1016/j.ijepes.2012.06.026

Peukert, W. (1897). Über die abhänigkeit der kapazität von der entladestromstärke bei.27, 287-288.

Pollet, B. G., Staffell, I., \& Shang, J. L. (2012). Current status of hybrid, battery and fuel cell electric vehicles: From electrochemistry to market prospects. Electrochimica Acta, 84, 235-249.

Sorrentino, M., Pianese, C., \& Maiorino, M. (2013). An integrated mathematical tool aimed at developing highly performing and cost-effective fuel cell hybrid vehicles. Journal of Power Sources, 221(0), 308317. doi:10.1016/j.jpowsour.2012.08.001

Wang, C., Zhou, S., Hong, X., Qiu, T., \& Wang, S. (2005). A comprehensive comparison of fuel options for fuel cell vehicles in china. Fuel Processing Technology, 86(7), 831-845. 